\title{
Ustekinumab in treatment of Crohn's disease: design, development, and potential place in therapy
}

\author{
This article was published in the following Dove Press journal: \\ Drug Design, Development and Therapy \\ II November 2016 \\ Number of times this article has been viewed
}

\author{
Parakkal Deepak \\ Edward V Loftus Jr \\ Division of Gastroenterology and \\ Hepatology, Mayo Clinic College \\ of Medicine, Rochester, MN, USA
}

Correspondence: Parakkal Deepak Division of Gastroenterology and Hepatology, Mayo Clinic College of Medicine, 200 First Street SW, Rochester, MN 55905, USA Tel + I 5072842407 Email deepak.parakkal@mayo.edu

\begin{abstract}
Crohn's disease is characterized by a dysregulation of both innate and adaptive immunity responses. Interleukin-12/23 (IL-12/23) pathway has been found to be a major driver of inflammation in adaptive immune responses. Ustekinumab is a fully human immunoglobulin G1 kappa monoclonal antibody that blocks the p40 subunit of IL-12 and IL-23 and prevents their interaction with their cell surface receptor and further cytokine activation. It is currently approved in the management of plaque psoriasis and psoriatic arthritis. Very promising data have emerged through phase II and phase III trials (UNITI-1, UNITI-2, and IM-UNITI) for both induction and maintenance of clinical response and remission in moderate-to-severe Crohn's disease, resulting in approval by the Food and Drug Administration for this condition. This article reviews the immunology of the IL-12/23 pathway, available data regarding the initial designing of ustekinumab, drug development through clinical trials including pharmacokinetics, efficacy, and safety, and its potential place in the treatment of Crohn's disease.
\end{abstract}

Keywords: ustekinumab, Crohn's disease, inflammatory bowel disease, interleukin-12/23 monoclonal antibody, interleukin-12, interleukin-23

\section{Introduction}

Crohn's disease is a chronic immune-mediated condition that is characterized by a relapsing nature and involvement of the gastrointestinal system from mouth to anus. ${ }^{1}$ Although the pathophysiologic mechanisms have not been completely understood, the disease is likely a result of the interaction between commensal flora in the gut and host microbial defenses in a genetically predisposed individual. ${ }^{2}$ These processes culminate in a dysregulated immune response. The microbial defenses include the mucosal barrier, the innate and adaptive immunity, that result in a transmural inflammatory response in Crohn's disease. The bowel inflammation results in symptoms such as diarrhea, abdominal pain, and fatigue, and a substantial minority may experience extra-intestinal manifestations. Over the long term, the transmural inflammatory response leads to the development of strictures and/or fistulae that require surgeries and/or hospitalizations.

Medical therapy in Crohn's disease has initially focused on nonspecific immunosuppressive therapies including thiopurines and methotrexate., ${ }^{3,4}$ The treatment paradigm has since shifted toward targeting specific pathways of inflammation. Ustekinumab (Stelara; Janssen Biotech, Horsham, PA, USA) is a fully human immunoglobulin G1 (IgG1) kappa monoclonal antibody that blocks interleukin-12 (IL-12) and IL-23 and has been previously approved for the treatment of moderate-to-severe plaque 
psoriasis (2009) and active psoriatic arthritis (PsA; 2013). ${ }^{5-11}$ The results of phase II and phase III trials for ustekinumab treatment of Crohn's disease appear very promising. ${ }^{12-14}$ This has led to its approval by the Food and Drug Administration (FDA) for the treatment of moderately to severely active Crohn's disease in adults ( $\geq 18$ years) who have failed or were intolerant to treatment with immunomodulators or corticosteroids but never failed treatment with tumor necrosis factor (TNF) antagonists, or who failed or were intolerant to treatment with $\geq 1$ TNF antagonists. ${ }^{15}$ The approved dosing for induction regimen is weight based: $260 \mathrm{mg}$ intravenous (IV) for $<55 \mathrm{~kg}$ body weight, $390 \mathrm{mg}$ IV for $55-85 \mathrm{~kg}$, and $520 \mathrm{mg}$ IV for $>85 \mathrm{~kg}$ followed by maintenance with $90 \mathrm{mg}$ subcutaneous (SC) every 8 weeks. This study reviews briefly the immunology of the interleukin-12/23 (IL-12/23) pathway, available data regarding the initial design of ustekinumab, drug development through clinical trials including the pharmacokinetics, efficacy, and safety, and its potential place in the treatment of Crohn's disease.

\section{Design}

\section{Immunology of the IL- I 2/23 pathway}

Crohn's disease is characterized by a dysregulation of both innate and adaptive immunity responses, with perturbations in adaptive immunity more likely driving the long-term tissue damage. ${ }^{2}$ Adaptive immune responses are governed by a combination of resident and recruited cell populations, including mucosal B cells producing secretary IgA and $\mathrm{IgG}$, a complex mixture of $\mathrm{T}$ cells dominated by a Th1, Th17, or Th2 phenotype, and regulatory T/B cells. ${ }^{2}$ Crohn's disease has been shown to have a Th1 profile, unlike ulcerative colitis, which seems to exhibit a Th2type-like cytokine profile. ${ }^{2}$

IL-12 and IL-23 are major drivers of the adaptive immune response. IL-12 is a cytokine that is primarily produced by phagocytic and dendritic cells in response to microbial stimulation and drives cell-mediated immunity by activating T-cell proliferation by Th1 cells. ${ }^{16,17}$ Cytokines secreted from Th1 cells include IL-2, interferon $\gamma$ (IFN $\gamma$ ), and TNF $\alpha$ and $\beta$. IFN $\gamma$ further amplifies the inflammatory cascade, leading to expression of multiple cytokines (IL-7, IL-15, IL-18, and IL-21) that cause further proliferation of Th1 cells. The Th1 subset of $\mathrm{T}$ cells promotes cell-mediated immunity to intracellular pathogens, delayed-type hypersensitivity, and macrophage activation. ${ }^{16}$ IL-12 is a heterodimer comprising covalently linked p40 and p35 protein subunits which then bind to a heterodimeric receptor complex consisting of IL-12 receptor (IL-12R) $\beta 1$ and IL-12R $\beta 2$ chains expressed on the surface of $\mathrm{T}$ cells or natural killer (NK) cells. ${ }^{18}$
In contrast, IL-23 plays a major role in the expansion of committed Th17 cells, which are fundamentally dependent on the transcription factor retinoid-related orphan. ${ }^{19,20}$ Cytokines secreted from Th17 cells (IL-17A, IL-17F, IL-21, IL-22, IL-26, chemokine ligand 20, and IFN $\gamma$ ) exhibit increased tissue expression in Inflammatory bowel disease (IBD) and Crohn's disease (CD). ${ }^{21}$ The IL-23 receptor is expressed on T cells, NK cells, and innate lymphoid cells, and also at low levels on monocytes, macrophages, and dendritic cells. ${ }^{22,23}$ The ligand IL-23 is also a heterodimeric molecule, composed of a p40 and p19 chain, which are linked by a disulfide bond. The p40 chain is shared with IL-12, where it pairs with a p35 polypeptide. $^{24}$

Neurath et al demonstrated that neutralization of the p40 protein was protective against the development of trinitrobenzene sulfonic acid (TNBS)-induced experimental colitis in mice..$^{25}$ This effect was ascribed to neutralization of IL-12. However, it was subsequently shown that CD40-induced colitis, but not wasting disease or serum proinflammatory cytokine production, depended on IL-23 p19 secretion, whereas IL-12 p35 secretion controlled wasting disease in this model. ${ }^{26}$ Subsequent studies in LacZ knockin mice deficient of IL-23 p19 showed more severe colitis induced by TNBS than in wild-type mice, with amelioration of colitis with in vivo blockade of IL-12 p40. ${ }^{27}$ These studies highlighted that both IL-12 and IL-23 might have a role in intestinal inflammation depending on the experimental mouse model. ${ }^{28,29}$

\section{Mechanism of action}

Ustekinumab is a monoclonal antibody with a human IgG1 heavy chain and a kappa light chain. It binds to the p40 subunit of IL-12 and IL-23 and prevents their interaction with the cell surface IL-12R $\beta 1$ receptor, subsequently inhibiting IL-12- and IL-23-mediated cell signaling, activation, and cytokine production (Figure 1).

The binding epitope for ustekinumab is located in the D1 domain of the p40 subunit, which is spatially distant from IL-12p35 and IL-23p19. ${ }^{24}$ Ustekinumab was shown to bind IL-12 and IL-23, equally neutralizing IL-12-mediated responses (intracellular phosphorylation of STAT4, cell surface marker expression, and IFN $\gamma$ cytokine production) and IL-23-mediated responses (intracellular STAT3 phosphorylation and IL-17A, IL-17F, and IL-22 cytokine protein production).

\section{Drug development Pharmacokinetics}

The pharmacokinetic properties of ustekinumab have mainly been defined in psoriasis. The characteristics of ustekinumab 

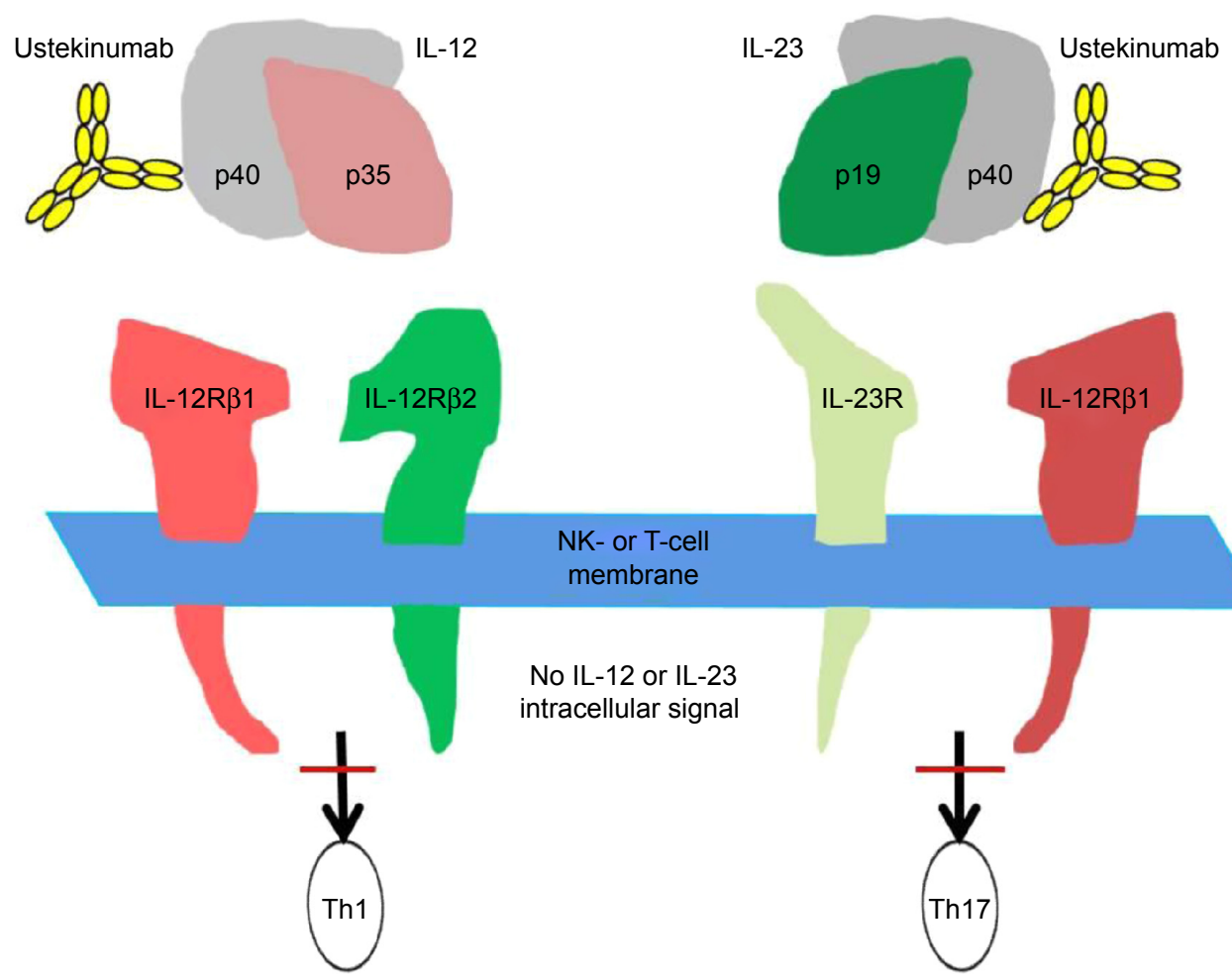

No IL-12 or IL-23 intracellular signal

Figure I Ustekinumab binds to the $\mathrm{p} 40$ subunit of IL- 12 and IL-23, preventing binding with the NK- or T-cell surface IL-I2R $\beta$ I, and inhibiting IL- I2 signaling and further activation of ThI subset of T cells as well as IL-23 signaling and further activation of ThI7 subset of T cells.

Note: Image not drawn to scale; Adapted by permission from Macmillan Publishers Ltd: Nat Biotechnol. Benson JM, Sachs CW, Treacy G, et al. Therapeutic targeting of the IL-I $2 / 23$ pathways: generation and characterization of ustekinumab. 20I I;29(7):6I5-624. Copyright (20I I). ${ }^{24}$

Abbreviations: IL, interleukin; IL-I2RßI, IL- 22 receptor $\beta$ I; NK, natural killer.

are similar to those of human endogenous IgG1 with IV and $\mathrm{SC}$ administration displaying an extended elimination half-life of $\sim 3$ weeks. ${ }^{30}$ The extended elimination half-life is thought to be primarily due to the salvage effect of the neonatal $\mathrm{Fc}$ receptor that protects antibody proteins from lysosomal degradation. ${ }^{30}$ In psoriasis patients, the median time to reach the maximum serum concentration after a single $\mathrm{SC}$ dose is dose-dependent, varying from 7 days $(90 \mathrm{mg})$ to 13.5 days $(45 \mathrm{mg}){ }^{31}$ The mean half-life ranged from 14.9 to 45.6 days across all psoriasis studies following IV and $\mathrm{SC}$ administration. The mean volume of distribution during the terminal phase following a single IV administration to patients with psoriasis ranged from 56.1 to $82.1 \mathrm{~mL} / \mathrm{kg}$. The mean systemic clearance of a single IV administration of ustekinumab to psoriasis patients ranged from 1.90 to $2.22 \mathrm{~mL} / \mathrm{day} / \mathrm{kg}$. The estimated bioavailability following SC administration is $\sim 57 \%{ }^{31,32}$

Interpatient variability related to differences in body mass index, serum albumin concentration, concomitant immunosuppressive use, severity of inflammation, and disease type has been described with monoclonal antibodies. ${ }^{33}$ Using population pharmacokinetic modeling with serum ustekinumab concentration data across two phase III trials in patients with moderate-to-severe plaque psoriasis
(PHOENIX 1 and PHOENIX 2), body weight, presence of diabetes mellitus, and antibodies to ustekinumab were the predominant determinants of drug clearance. ${ }^{34}$ The potential effect of 28 concomitant medications, including amoxicillin and omeprazole, on the pharmacokinetics of ustekinumab was assessed, and none of these medications had a significant effect on the apparent clearance of ustekinumab. ${ }^{35}$

\section{Efficacy}

\section{Data from psoriasis}

PHOENIX 1 and PHOENIX 2 were phase III, multicenter, randomized, double-blind, placebo-controlled, parallel studies that were performed to evaluate the SC administration of ustekinumab in patients with moderate-to-severe psoriasis. ${ }^{78}$ In PHOENIX 1, 766 patients were randomized to receive $45 \mathrm{mg}$ ustekinumab ( $\mathrm{n}=255$ ) or $90 \mathrm{mg}$ ustekinumab $(n=256)$ at baseline and week 4 , followed by every 12 weeks, or to receive placebo at week 0 and $4(\mathrm{n}=255)$, with crossover to receive either 45 or $90 \mathrm{mg}$ ustekinumab at week $12 .{ }^{7}$ The primary endpoint in this study was the percentage of patients achieving Psoriasis Area Severity Index (PASI) 75 at week 12, using an intention to treat analysis. At week 12, PASI 75 was achieved in 171 of those receiving $45 \mathrm{mg}$ (67.1\%), and 170 of those receiving $90 \mathrm{mg}$ of ustekinumab 
(66.4\%) compared with 8 placebo-treated patients $(3.1 \%)$. In PHOENIX 2, a total of 1,230 patients were similarly randomized to receive 45 or $90 \mathrm{mg}$ ustekinumab or placebo at baseline, week 4, and then every 12 weeks or placebo at baseline and week 4 , again with placebo crossover to receive 45 or $90 \mathrm{mg}$ ustekinumab at week $12 .{ }^{8}$ The primary endpoint was the proportion of patients achieving PASI 75 at week 12, and this was met in 273 patients receiving $45 \mathrm{mg}$ ustekinumab (66.7\%), and 311 receiving $90 \mathrm{mg}$ ustekinumab (75.7\%), compared with 15 receiving placebo (3.7\%).

Based on the above studies, ustekinumab was approved for the treatment of chronic plaque psoriasis in the United States (October 2009), Canada (December 2008), and the European Union (January 2009). ${ }^{6}$ The current licensed dosage regimen is $45 \mathrm{mg}$ ustekinumab at baseline, 4 weeks, and every 12 weeks in those weighing $\leq 100 \mathrm{~kg}$, and $90 \mathrm{mg}$ ustekinumab at the same intervals for those $>100 \mathrm{~kg}$.

The comparative effectiveness of ustekinumab was tested head-to-head with etanercept in patients with moderateto-severe psoriasis in a phase III trial. ${ }^{36}$ The study design involved adaptive randomization with study investigators (but not the patient) blinded to treatment allocation. In this study, 903 patients were randomized to receive SC ustekinumab 45 or $90 \mathrm{mg}$ at week 0 and 4 , or etanercept $50 \mathrm{mg} \mathrm{SC}$ twice weekly for 12 weeks. The patients who were randomly assigned to ustekinumab received double injections (one injection of active treatment and one injection of placebo) to maintain blinding for the dose. The superiority of ustekinumab over etanercept was demonstrated at week 12 with those receiving ustekinumab 45 or $90 \mathrm{mg}$ achieving PASI 75 in $67.5 \%$ and $73.8 \%$ of patients, respectively, compared with $56.8 \%$ of those receiving etanercept $(P=0.01$ and 0.001 , respectively).

\section{Data from PsA}

PSUMMIT 1 and 2 were phase III, multicenter, doubleblind, placebo-controlled trials performed to evaluate the $\mathrm{SC}$ administration of ustekinumab in patients with active PsA. ${ }^{9,10}$ In PSUMMIT1, patients with active PsA were randomly assigned to $45 \mathrm{mg}$ ustekinumab ( $\mathrm{N}=205), 90 \mathrm{mg}$ ustekinumab $(\mathrm{N}=204)$, or placebo $(\mathrm{N}=206)$ at week 0,4 , and every 12 weeks thereafter. ${ }^{9}$ The primary endpoint was $\geq 20 \%$ improvement in the American College of Rheumatology (ACR20) criteria at week 24. A greater percentage of patients in both the 45 and $90 \mathrm{mg}$ ustekinumab groups achieved ACR20 at week 24 compared to the placebo group (42.4\%, $49.5 \%$, and $22.8 \%$, respectively, $P<0.0001$ for both comparisons) with responses maintained at week 52. PSUMMIT 2 comprised patients with active PsA despite treatment with conventional agents and/or TNF antagonists. ${ }^{10}$ Patients were randomized to ustekinumab 45 or $90 \mathrm{mg}$ at week 0,4 , and then every 12 weeks or placebo at week 0,4 , and 16 and then crossover to ustekinumab $45 \mathrm{mg}$ at week 24, 28, and 40. The primary endpoint of ACR20 was achieved more often in the ustekinumab-treated $(43.8 \%$ combined) than placebo-treated $(20.2 \%)$ patients at week $24(P<0.001)$. Even among patients previously treated with $\geq 1$ TNF antagonist, ACR20 response was higher in the ustekinumab-treated (35.6\% combined) than placebo-treated patients $(14.5 \%)$ at week $24(P<0.01)$.

\section{Data from Crohn's disease}

A phase IIa trial was conducted in TNF antagonist-naïve and -experienced Crohn's disease patients (Table 1). ${ }^{14}$ In the double-blind crossover component of this trial, 104 patients were randomized to four groups. Group 1 received SC placebo at weeks $0-3$, followed by $90 \mathrm{mg}$ ustekinumab at weeks 8-11; group 2 SC $90 \mathrm{mg}$ ustekinumab at weeks 0-3, then placebo at weeks 8-11; group 3 IV placebo at week 0 , followed by $4.5 \mathrm{mg} / \mathrm{kg}$ ustekinumab at week 8 ; and group 4 IV $4.5 \mathrm{mg} / \mathrm{kg}$ ustekinumab at week 0 , then placebo at week 8 . Clinical response (at week 8 , primary endpoint) was defined as a 70-point decrement in the Crohn's disease activity index (CDAI) score and a minimum reduction of $25 \%$ from the baseline score. Clinical response in patients who received ustekinumab and placebo was $53 \%$ and $30 \%(P=0.02)$, respectively, at weeks 4 and 6 , and $49 \%$ and $40 \%(P=0.34)$, respectively, at week 8 . In a subgroup of patients who were previously given infliximab (neither primary nor secondary nonresponders), clinical response to ustekinumab was significantly greater than in the group given placebo $(P<0.05)$ through week 8 . In the open-label portion of the trial, a second population of 27 patients (primary and secondary nonresponders to infliximab) was randomized 1:1 to receive a single $4.5 \mathrm{mg} / \mathrm{kg}$ IV infusion or 4 weekly SC injections of $90 \mathrm{mg}$ ustekinumab. At week 8, clinical response in the SC and IV ustekinumab groups was $43 \%$ and $54 \%$, respectively. The clinical response observed with ustekinumab was paralleled by a decrease in the serum C-reactive protein (CRP) concentration, with higher baseline CRP values leading to larger treatment effects with ustekinumab, especially in infliximab-experienced patients. ${ }^{37}$

In a subsequent double-blind, placebo-controlled phase IIb trial of ustekinumab, 526 patients with moderateto-severe $\mathrm{CD}$ who had previously failed $\geq 1 \mathrm{TNF}$ antagonists were randomized to receive a single dose of 1,3 , or $6 \mathrm{mg} / \mathrm{kg}$ 


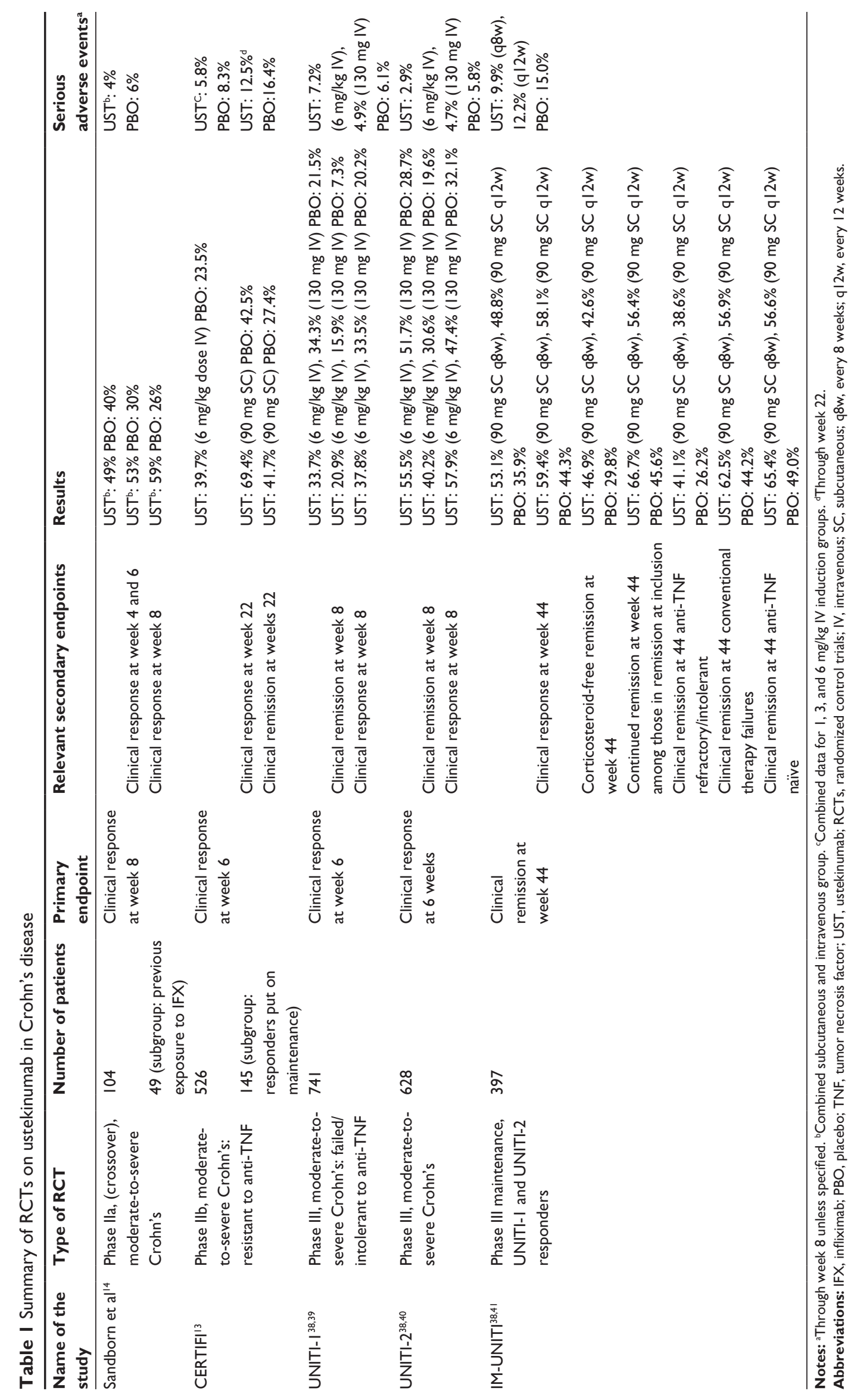


of IV ustekinumab or placebo. ${ }^{13}$ At week 6, 36.6\%, 34.1\%, and $39.7 \%$ of patients in the 1,3 , and $6 \mathrm{mg} / \mathrm{kg}$ of ustekinumab groups, respectively, had a clinical response (defined as 100-point decrease in CDAI score from baseline) compared with $23.5 \%$ of patients in the placebo group $(P=0.005$ for the comparison with the $6 \mathrm{mg} / \mathrm{kg}$ group). In this study, responders to ustekinumab at week 6 were re-randomized to maintenance therapy with $90 \mathrm{mg}$ of SC ustekinumab or placebo at weeks 8 and 16. In the maintenance phase of the study, ustekinumab was superior to placebo for both clinical remission, defined as CDAI score $<150$ points $(41.7 \%$ vs $27.4 \%, P=0.03)$, and response $(69.4 \%$ vs $42.5 \%, P<0.001)$ at 22 weeks. ${ }^{13}$

Following the promising results of the phase II trials, a couple of 8 week phase III induction trials (UNITI-1 and 2) and a 44 week phase III maintenance trial (IM-UNITI) have been conducted (Figure 2). ${ }^{38-41}$ In UNITI-1, 741 patients with moderate-to-severely active Crohn's disease (CDAI score, 220-450) who previously failed or were intolerant to at least 1 TNF antagonist were randomized (1:1:1) at week 0 to a single dose of IV placebo, ustekinumab $130 \mathrm{mg}$, or weight-based tiered ustekinumab dosing approximating $6 \mathrm{mg} / \mathrm{kg}$ (260 mg [weight $\leq 55 \mathrm{~kg}$ ], $390 \mathrm{mg}$ [weight $>55 \mathrm{~kg}$ and $\leq 85 \mathrm{~kg}$ ], or $520 \mathrm{mg}$ [weight $>85 \mathrm{~kg}$ ]). ${ }^{39}$ The primary endpoint in UNITI-1 was clinical response at week 6, defined as reduction from baseline in the CDAI score of $>100$ points; patients with baseline CDAI score $>220$ to $<248$ points were considered in the clinical response if a CDAI score of $<150$ was present. Major secondary induction endpoints were clinical remission (CDAI score $<150$ points) at week 8, clinical response (CDAI 100-point response) at week 8 , and $\geq 70$-point CDAI decrease at week 3 and at week 6 . At week 8, patients either transitioned to the IM-UNITI maintenance study or were followed to week 20 . The primary endpoint (clinical response at week 6) was observed in 33.7\% of those receiving weight-based dosing $(6 \mathrm{mg} / \mathrm{kg})$ and $34.3 \%$ of the $130 \mathrm{mg}$ ustekinumab groups vs $21.5 \%$ in placebo $(P=0.003$ and 0.002 , respectively). The secondary endpoint of clinical remission at week 8 was observed in $20.9 \%$ of the $6 \mathrm{mg} / \mathrm{kg}$ group and $15.9 \%$ of the $130 \mathrm{mg}$ group vs $7.3 \%$ on placebo $(P<0.001$ and $P=0.003$, respectively). Clinical response at week 8 was seen in $37.8 \%$ of the $6 \mathrm{mg} / \mathrm{kg}$ and $33.5 \%$ of the $130 \mathrm{mg}$ ustekinumab groups, vs $20.2 \%$ on placebo (each $P \leq 0.001$ ).

UNITI-2 ( $=628)$ was another induction trial of ustekinumab specifically in moderately to severely active patients who had previously failed corticosteroids and/or immunomodulators and were either naïve to or had been exposed to TNF antagonists, but had not failed such biologic therapy..$^{40}$ These patients also had objective evidence of active Crohn's disease (ie, at least one of serum CRP concentration $>3.0 \mathrm{mg} / \mathrm{L}$, fecal calprotectin $>250 \mathrm{mg} / \mathrm{kg}$, or endoscopic ulcerations of ileum and/or colon). Patients participating in the phase III UNITI-2 study received ustekinumab or placebo at doses similar to UNITI-1 and were assessed with similar primary and secondary endpoints. In UNITI-2, greater proportions of patients

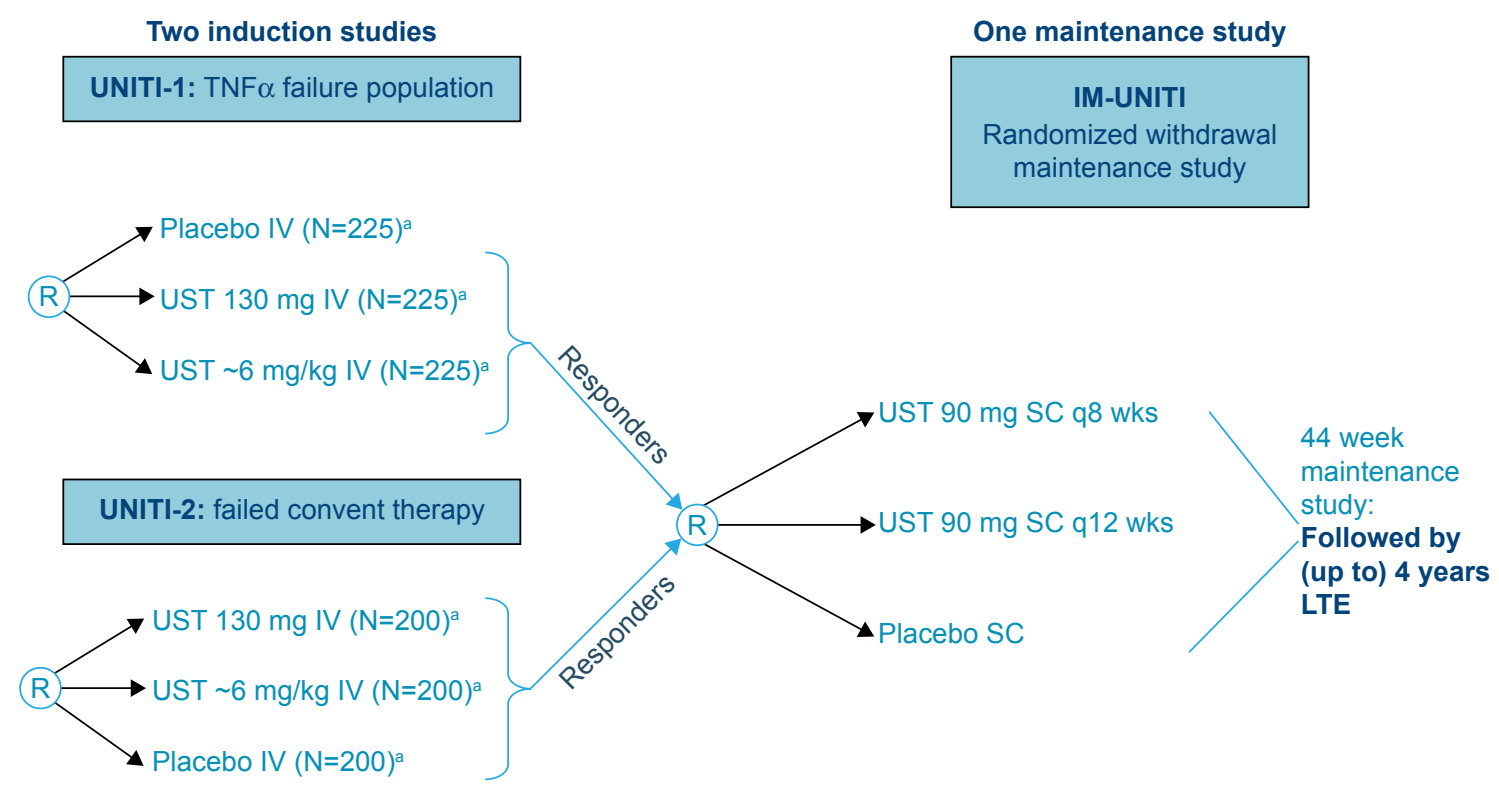

Figure 2 Overall structure of UNITI phase III program.

Note: ${ }^{2}$ Subjects randomized to placebo and subjects who are non-responders to ustekinumab are eligible for non-randomized maintenance dosing after completion of the induction study.

Abbreviations: LTE, long-term extension; TNF, tumor necrosis factor; UST, ustekinumab; IV, intravenous; SC, subcutaneous; q8 wks, every 8 weeks; qI 2 wks, every 12 weeks. 
who received ustekinumab $130 \mathrm{mg}(51.7 \%)$ and $6 \mathrm{mg} / \mathrm{kg}$ $(55.5 \%)$ demonstrated response at week 6 (primary endpoint) compared with $28.7 \%$ who received placebo $(P<0.001$ for both comparisons). At week $8,30.6 \%$ and $40.2 \%$ of patients receiving ustekinumab $130 \mathrm{mg}$ and $\sim 6 \mathrm{mg} / \mathrm{kg}$, respectively, achieved clinical remission, compared with $19.6 \%$ of patients receiving placebo ( $P=0.009$ and $P<0.001$, respectively). In addition, $47.4 \%$ of patients receiving ustekinumab $130 \mathrm{mg}$ and $57.9 \%$ of patients receiving $\sim 6 \mathrm{mg} / \mathrm{kg}$ achieved clinical response at week 8 , compared with $32.1 \%$ of patients receiving placebo $(P<0.001$ for both comparisons).

Induction trial completers participated in IM-UNITI, in which ustekinumab responders $(\mathrm{N}=397)$ were randomized to maintenance SC injections of $90 \mathrm{mg}$ ustekinumab every 8 weeks (q8w) or 12 weeks (q12w), or placebo. ${ }^{41}$ The primary endpoint for the maintenance trial was remission $($ CDAI <150) at week 44. Secondary endpoints at week 44 included clinical response, clinical remission among patients in clinical remission after ustekinumab induction, corticosteroid-free remission, and clinical remission in patients refractory or intolerant to TNF antagonists (UNITI-1 subgroup). Greater proportion of patients in the ustekinumab groups achieved clinical remission at week 44 compared with placebo $(53.1 \%$ and $48.8 \%$ in the $\mathrm{q} 8 \mathrm{w}$ and $\mathrm{q} 12 \mathrm{w}$ groups vs $35.9 \%$ on placebo; $P=0.005$ and 0.040 , respectively). Significantly greater proportions of patients also maintained clinical response at week 44 in the $\mathrm{q} 8 \mathrm{w}(59.4 \%)$ and $\mathrm{q} 12 \mathrm{w}$ (58.1\%) ustekinumab groups vs placebo $(44.3 \% ; P<0.05$ for both). The proportions of patients in clinical remission and not receiving concomitant corticosteroids at week 44 were significantly higher in the q8w group (46.9\%) and numerically higher in the q12w group (42.6\%) vs placebo (29.8\%; $P=0.004$ and nominal $P=0.035$, respectively). The treatment effect difference for $\mathrm{q} 8 \mathrm{w}$ versus placebo $(17.2 \%$, [95\% confidence interval $\{\mathrm{CI}\}: 5.32 \%, 29.71 \%]$ ) was numerically higher than that for $\mathrm{q} 12 \mathrm{w}$ group $(13.0 \%$, [95\% CI: $1.05 \%$, $24.87 \%]$ ). The q8w group had a significantly greater proportion of patients in remission at week 44 compared with placebo among patients who had failed conventional therapy (UNITI-2 subgroup). In the subset of patients refractory or intolerant to TNF antagonists (UNITI-1 subgroup), the proportion in clinical remission was numerically but not significantly greater than placebo for both dose groups.

\section{Real-world experience}

The open-label observational experience with ustekinumab prior to regulatory approval has been described in four studies (three published manuscripts and one abstract) from tertiary
IBD centers in North America and Europe. ${ }^{42-45}$ The experience from the IBD Mayo Clinic in Rochester, Minnesota (January 2008-August 2013) included 18 refractory Crohn's disease patients who had experienced failure of at least two TNF antagonists in $89 \%$ of patients, methotrexate in $83 \%$, and thiopurines in $89 \%$. Natalizumab had been used in $16.7 \%$ of patients prior to ustekinumab. Many of these patients had short bowel syndrome, were TPN-dependent, or had ostomies. The induction dose ranged from 45 to $270 \mathrm{mg} \mathrm{SC}$ at week 0 while the most common maintenance dose was $90 \mathrm{mg}$ SC every 8 weeks. The cumulative probabilities of any response at 1, 2, and 6 months were $11.1 \%, 38.9 \%$, and $44.4 \%$, respectively. The cumulative probability of loss of response among patients with partial or complete response was $25 \%$ at 1,3 , and 6 months. Mucosal healing was observed in 3 of the 8 patients $(37.5 \%)$ who had a repeat endoscopy.

The ustekinumab experience at McGill University, Montreal, Canada (March 2011-November 2013) included 38 Crohn's disease patients, all of whom had previously failed at least one TNF antagonist, and 95\% had failed $\geq 2 .{ }^{43}$ The induction dose varied from $45 \mathrm{mg}$ (weeks 0 and 4) to $90 \mathrm{mg}$ (weeks $0,1,2$, or 0,4 ), while maintenance doses varied between $45 \mathrm{mg}$ every 12 weeks and $90 \mathrm{mg}$ every 4, 8, or 12 weeks. Initial clinical response (at week 12 or first follow-up visit) was achieved in $73.7 \%$, while maintenance of response was seen in $80 \%$ at 6 months, $88.9 \%$ at 12 months, and $71 \%$ at last follow-up. Dose escalation was required in $47.7 \%$ of the patients and was successful in $61.1 \%$ of them.

The ustekinumab experience (March 2011 to December 2014) across tertiary French and Swiss IBD centers that are part of the Groupe d'Etude Thérapeutique des Affections Inflammatoires du tube Digestif included 122 consecutive CD patients all of whom had failed at least one, 92\% failed two, $37 \%$ failed three, and $2 \%$ all four TNF antagonists. ${ }^{44}$ Clinical benefit from ustekinumab was assessed within 3 months, defined as a significant improvement in CD-related clinical symptoms and laboratory tests, associated with complete weaning from steroids, without surgery, or new immunosuppressant introduction. This was seen in $65 \%$ of the patients within 3 months, with maintenance of clinical benefit for 6 and 12 months after introduction of ustekinumab in 93\% and $68 \%$, respectively. Additionally, concomitant immunosuppressant therapy at study inclusion increased the odds for a clinical benefit from ustekinumab (odds ratio, 5.43; 95\% CI, 1.14-25.77; $P=0.03$ ).

The open-label experience across 42 Spanish tertiary IBD centers (March 2010 to December 2014) included 116 
consecutive patients with Crohn's disease who failed at least one immunomodulator and one TNF antagonist and received treatment with ustekinumab for at least 2 months. ${ }^{45}$ Clinical response (decrease in Harvey-Bradshaw index score by $\geq 3$ points from the baseline) after induction dosing of ustekinumab was achieved in $84 \%$ of the patients. The clinical benefits at 6, 12 months and at the end of the follow-up were $76 \%, 64 \%$, and $58 \%$, respectively. Dose escalation was required in $10 \%$ of the patients and effective in the majority (73\%) of those patients. Perianal disease also improved in 11 of 18 patients with active perianal disease $(61 \%)$.

\section{Endoscopic response as treatment endpoint}

There are limited data on mucosal healing with ustekinumab. In the CERTIFI study, 8 of 41 patients in the ustekinumab group (19.5\%) achieved mucosal healing compared to 1 in the placebo group. ${ }^{13}$ In the study from McGill, endoscopic improvement was achieved in 10 of 13 cases $(76.9 \%)$; mucosal healing was demonstrated in 2 of these patients. ${ }^{43}$

\section{Immunogenicity and therapeutic drug monitoring}

In the CERTIFI trial, only 3 of the 427 Crohn's disease patients with samples for analysis $(0.7 \%)$ showed antibodies to ustekinumab through week $36 .{ }^{13}$ Likewise, the incidence of antibodies to ustekinumab was low $(0.2 \%)$ in the UNITI studies across both dose groups. ${ }^{46}$ In IM-UNITI, the incidence of antibodies to ustekinumab through week 44 was similarly low $(27 / 1,154$ patients, $2.3 \%) .{ }^{47}$ In a real-world experience at McGill University, none of the 49 patients tested had detectable antibodies to ustekinumab at $>6$ months usage. ${ }^{48}$

Across the three phase III trials, serum ustekinumab concentrations were dose-proportional and showed a positive association with clinical remission at week 8 (UNITI-1 and UNITI-2) and week 24 (IM-UNITI). ${ }^{47}$ At the end of induction (week 8), median ustekinumab concentrations were 2.1 and $6.4 \mu \mathrm{g} / \mathrm{mL}$ for the $130 \mathrm{mg}$ and $6 \mathrm{mg} / \mathrm{kg}$ dose groups, respectively. Additionally, the median steady-state trough serum ustekinumab concentrations over time in the q8w group (1.97-2.24 $\mu \mathrm{g} / \mathrm{mL})$ were 3-fold higher than in the $\mathrm{q} 12 \mathrm{w}$ group $(0.61-0.76 \mu \mathrm{g} / \mathrm{mL})$. In a real-world analysis of 59 patients from McGill University, a serum ustekinumab level $>4.5 \mu \mathrm{g} / \mathrm{mL}$ was associated with endoscopic response (72.2\% sensitivity, $83.3 \%$ specificity; $P=0.0006$; area under curve, 0.782). ${ }^{48}$ This level (compared to lower levels) was also associated with a composite outcome of steroid-free clinical remission and endoscopic response (50\% vs $15 \%$,
$P=0.024$ ). Additionally, a ustekinumab level $>5 \mu \mathrm{g} / \mathrm{mL}$, compared to lower levels, was associated with normal serum CRP (63.6\% vs 33\%, $P=0.024)$.

\section{Adverse events (AEs)}

\section{Preclinical}

The data for the risk of cancers in murine studies are conflicting because of the antitumor activity of IL-12 contrasting with the tumor promotion effect of IL-23..$^{49,50}$ However, preclinical toxicology testing conducted in cynomolgus monkeys did not show significant adverse effects with IV or SC ustekinumab administered biweekly at doses as high as $45 \mathrm{mg} / \mathrm{kg}$ for up to 6 months. ${ }^{51}$

\section{Data from psoriasis}

In PHOENIX 1, the most common AEs were reported as upper respiratory tract infections, nasopharyngitis, headache, and arthralgia. ${ }^{7}$ AEs were reported in $54.5 \%$ of those receiving ustekinumab and $48.2 \%$ of those receiving placebo. Serious AEs occurred in $1.2 \%$ of the patients receiving ustekinumab and $0.8 \%$ of the patients receiving placebo. These were most common infections and cardiac events. No malignancies were reported during the placebo-controlled phase, although they were reported during the crossover phase (one case each of prostate cancer and thyroid cancer) and the withdrawal phase (one case of colon cancer).

In PHOENIX 2, during the placebo-controlled phase, AEs were similar in the 45 and $90 \mathrm{mg}$ group and the placebo group. ${ }^{8}$ The most common AEs were similar to PHOENIX 1 in addition to injection site erythema. Serious AEs were similar in type in all populations, with the most common events reported as infections and cardiac disorders. Through the three phases, one case each of basal cell skin cancer and squamous cell cancer of the tongue were reported in the ustekinumab group.

To evaluate a dose-dependent relationship with AEs and evaluate for cumulative exposure-dependent AEs, 3,117 patients from the four randomized, blinded, phase II and III ustekinumab studies in psoriasis were followed for up to 5 years. ${ }^{52}$ At year 5 , event rates per 100 patient years (45, $90 \mathrm{mg}$, respectively) were comparable for overall AEs (242.6, 225.3), serious AEs (7.0, 7.2), serious infections (SIs; $0.98,1.19)$, nonmelanoma skin cancers $(0.64,0.44)$, other malignancies $(0.59,0.61)$, and major cardiovascular events $(0.56,0.36)$. In this study, the rates of other malignancies (excluding nonmelanoma skin cancers) were comparable with those expected in the general US population (standardized incidence ratio, 0.98; 95\% CI, 0.74-1.29). 
The risk of AEs was further evaluated in a real-world setting using the Psoriasis Longitudinal Assessment and Registry (PSOLAR) containing data on 4,364 patients who had received ustekinumab for psoriasis. ${ }^{53}$ The cumulative incidence rates for malignancy, major cardiovascular events, SI, or mortality with ustekinumab were comparable to or lower than other biologics, and multivariate analyses did not show any association between these AEs and ustekinumab exposure. Reversible posterior leukoencephalopathy syndrome (RPLS) is a rare, generally reversible neurological syndrome that can present with acute onset of headache, visual disturbances, altered mental status, and seizures. ${ }^{54}$ Transient cerebral edema without infarction is usually seen on computed tomography or magnetic resonance images in the parietal and/or occipital lobes of the brain. The relationship of RPLS with ustekinumab is unclear, and a single case has been reported in a 65-year-old woman who developed RPLS after 12 doses over 2 years. ${ }^{11,55}$

\section{Data from Crohn's disease}

In the phase IIa study, the rate of serious AEs was similar between the ustekinumab and placebo groups. ${ }^{14}$ Throughout the induction and maintenance phase, only 1 case of prostate cancer (with increased prostate-specific antigen levels before study entry) and 2 cases of SIs (viral gastroenteritis and disseminated histoplasmosis) were recorded in patients receiving ustekinumab.

In the phase IIb study, common non-gastrointestinal AEs included headache, arthralgia, and nasopharyngitis. ${ }^{13}$ The rates of SIs were similar between the ustekinumab and placebo groups. These occurred in 6 patients ( 5 receiving ustekinumab $6 \mathrm{mg} / \mathrm{kg}$ and $1 \mathrm{in} 1 \mathrm{mg} / \mathrm{kg}$ dose) during induction and 4 in the maintenance phase. These included Clostridium difficile infection, viral gastroenteritis, urinary tract infection, anal abscess, vaginal abscess, and a staphylococcal infection in a central catheter. Basal cell carcinoma developed in 1 patient receiving ustekinumab. No deaths, major cardiovascular events, tuberculosis (TB), or other serious opportunistic infections were reported.

In the UNITI-1 study, the proportion of patients with AEs, serious AEs, and infections were similar in the ustekinumab and placebo groups. ${ }^{39}$ One significant opportunistic infection (Listeria meningitis) was reported in the group receiving $6 \mathrm{mg} / \mathrm{kg}$ ustekinumab. No malignancies, deaths, major adverse cardiovascular events, or TB occurred in ustekinumab-treated patients through week 20. Similar results were reported from the UNITI-2 study, with the proportion of patients with AEs, serious AEs, and infections (including SIs) similar to placebo. ${ }^{40}$ No malignancies, deaths, opportunistic infections, or TB occurred.

In the 44 week IM-UNITI trial, similar proportions of patients with AEs were seen across treatment groups (81.7\% and $80.3 \%$ for ustekinumab q8w and $\mathrm{q} 12 \mathrm{w}$, respectively, vs $83.5 \%$ placebo). ${ }^{41}$ The proportions of patients with serious AEs were $9.9 \%, 12.2 \%$, and $15.0 \%$ among the $\mathrm{q} 8 \mathrm{w}, \mathrm{q} 12 \mathrm{w}$, and placebo groups, respectively. SIs occurred in $2.3 \%, 5.3 \%$, and $2.3 \%$ of patients in the $\mathrm{q} 8 \mathrm{w}, \mathrm{q} 12 \mathrm{w}$, and placebo groups, respectively. Among the randomized population, no deaths or major adverse cardiovascular events were reported, and 2 patients reported malignancies ( 1 basal cell carcinoma in each of the placebo and $\mathrm{q} 8 \mathrm{w}$ groups). In the non-randomized population (those randomized to placebo in UNITI-1 or -2 or nonresponders to ustekinumab), a single case of active TB and a case of metastatic small bowel adenocarcinoma were reported.

The cumulative incidence rates of SIs (within 91 days of biologic administration) have also been evaluated among patients with self-reported IBD in the PSOLAR registry. ${ }^{56}$ The cumulative incidence rates of SI (per 100 patient years) for patients with IBD were higher than the total PSOLAR population (1.38 vs 0.93) for ustekinumab exposure. However, patients treated with ustekinumab had numerically lower rates of SIs than patients receiving infliximab, other biologic, and systemic therapies (1.38 vs 5.75, 4.32, and 3.47 , respectively) for psoriasis in the IBD subset. While concern has been raised for any major cardiac event with ustekinumab, a meta-analysis of randomized controlled clinical trials concluded that there was no significant difference in the rate of major cardiac events observed in patients receiving anti-IL-12/IL-23 antibodies or TNF antagonists. ${ }^{57}$ Finally, there has been one case report of central demyelination diagnosed 1 year after ustekinumab treatment in a 63-year-old patient who was also previously treated with an immunomodulator and three other TNF antagonists. ${ }^{58}$ There was no relationship between serum ustekinumab concentrations and the incidence of infections, SIs, or serious AEs following induction or maintenance treatment with ustekinumab in UNITI-1, UNITI-2, and IM-UNITI. ${ }^{47}$

\section{Data in pregnancy}

Ustekinumab is a US FDA class B medication, primarily based on animal studies in cynomolgus monkeys and with limited human data. ${ }^{6,59,60}$ Evaluation of the 29 pregnancies reported with maternal use of ustekinumab (at least 1 dose) from 4 psoriasis studies demonstrated no congenital anomalies, a rate of spontaneous abortion comparable to the 
general population (15\%-20\%), and no association between a longer duration of ustekinumab exposure before the reported pregnancy and adverse outcomes. ${ }^{61}$ In the PIANO registry, ustekinumab $(\mathrm{N}=3)$ has been detected to cross the placenta and detected in the infant at birth at ratios (to maternal serum levels) similar to infliximab and adalimumab. ${ }^{62}$ However, no association has been seen between detectable drug levels of biologics in the infant and the risk of infections, and breastfeeding is not contraindicated while on biologics. ${ }^{62}$ It would appear prudent to avoid live-virus vaccines for the first 6 months in infants born to mothers exposed to ustekinumab given the detectable drug levels. ${ }^{63}$

\section{Potential place in therapy}

Current options for biologics with regulatory approval in the management of CD include TNF antagonists (infliximab, adalimumab, and certolizumab pegol) and the anti-integrins, vedolizumab, and natalizumab. ${ }^{64} \mathrm{TNF}$ antagonists are currently positioned as first-line biologics in the management of moderate-to-severe CD. ${ }^{65}$ However, initial clinical response to TNF antagonists in trials has varied from 58\% to $64 \%$, with additional primary nonresponse in $\sim 13 \%-40 \%$ of patients and a secondary loss of response estimated to occur at a rate of $13 \%$ per year. ${ }^{66-68}$ This suggests the need for additional medications targeting other inflammatory pathways to treat patients who are primary nonresponders to TNF antagonists, are intolerant of the medications (due to AEs), or have a secondary nonresponse.

In the group of patients intolerant or refractory to TNF antagonists (UNITI-1), ustekinumab achieved clinical response (CDAI decrease $\geq 100$ points) at week 6 in $33.7 \%$ $(6 \mathrm{mg} / \mathrm{kg})$ to $34.3 \%(130 \mathrm{mg})$ versus $21.5 \%$ in placebo $\left(P=0.003\right.$ and 0.002 , respectively). ${ }^{39}$ The initial clinical response at week 6 is similar to that shown with vedolizumab ( $39.2 \%$ vs $22.3 \%$ with placebo, $P=0.001)$ in GEMINI 3, which was an induction trial enriched with anti-TNF refractory patients. ${ }^{69}$ Clinical remission $(\mathrm{CDAI}<150)$ at week 8 with ustekinumab (15.9\%-20.9\%) was also similar to the rates shown with vedolizumab at weeks 6 and $10(15.2 \%$ and $26.6 \%$ ) in this group of patients. During the maintenance phase of GEMINI 2 among initial responders to vedolizumab, $27.3 \%$ (every 4 week dosing) to $28 \%$ (every 8 week dosing) of the patients receiving vedolizumab were in clinical remission at week 52, in the group intolerant or refractory to TNF antagonists. ${ }^{70}$ Ustekinumab demonstrated a higher rate of clinical remission at week 44 in this group of patients, ranging from $38.6 \%$ (90 $\mathrm{mg} \mathrm{q} 12 \mathrm{w}$ ) to $41.1 \%$ (90 mg q8w), although IM-UNITI also demonstrated higher placebo remission rates than GEMINI-2 (26.2\% vs $12.8 \%){ }^{41}$ Ustekinumab also showed efficacy similar to vedolizumab in those who failed conventional therapy, factoring in the higher placebo response and remission rates in IM-UNITI.

The data from UNITI-1 and IM-UNITI demonstrate a clear role for ustekinumab among patients intolerant or refractory to TNF antagonists. The UNITI-2 data show that it may also potentially have a role among TNF antagonist naïve patients considering its favorable safety profile, potentially as a first-line biologic. However, this may be limited by cost considerations, especially with the introduction of biosimilars that are either FDA approved (infliximab biosimilar, CT-P13) or pending approval (adalimumab biosimilar, ABP 501). ${ }^{71,72}$

Specific subsets of Crohn's disease patients may be ideal candidates for ustekinumab therapy. These include patients with psoriasis and Crohn's disease as well as those who develop TNF-antagonist-induced psoriasis. ${ }^{73}$ Paradoxical psoriasis induced by TNF antagonists has been described to involve $1.7 \%-10 \%$ of described cohorts, and identified risk factors include cigarette smoking status, female sex, and younger age of initiation of TNF antagonist in certain cohorts. ${ }^{73-75}$ In a cohort of 434 IBD patients, 21 of whom developed psoriasis, all nine patients with Crohn's disease and severe psoriasiform lesions and/or TNF-antagonistinduced alopecia were successfully treated with ustekinumab. This study identified that IL-17A expression was significantly stronger in patients requiring ustekinumab than in patients responding to topical therapy $(P=0.001) .{ }^{73}$ Pyoderma gangrenosum (PG), including those recalcitrant to TNF antagonists and located in peristomal area, has been treated with ustekinumab. ${ }^{76-78}$ In a case report, the tissue sample from the PG lesion in the lower extremity showed a highly elevated expression of IL-23, and this patient was successfully treated with ustekinumab. ${ }^{78}$ Effects of the blockade of the IL-12/23 pathway on extra-intestinal manifestations are currently unknown, although studies have shown elevated serum IL-23 in Crohn's disease patients with associated arthritis and sacroiliitis. ${ }^{79}$ An algorithm for the use of ustekinumab based on current available literature is proposed in Figure 3.

\section{Specific IL-23 inhibition}

Efficacy comparable to blocking of the IL-12/23 axis has been shown in mouse models of psoriasis and multiple sclerosis. ${ }^{80}$ Available emerging data in psoriasis suggest that selective blockade of IL-23 may be critical in the pathogenesis of psoriasis more so than combined IL-12/23 blockade. ${ }^{81}$ A phase II head-to-head psoriasis study showed 


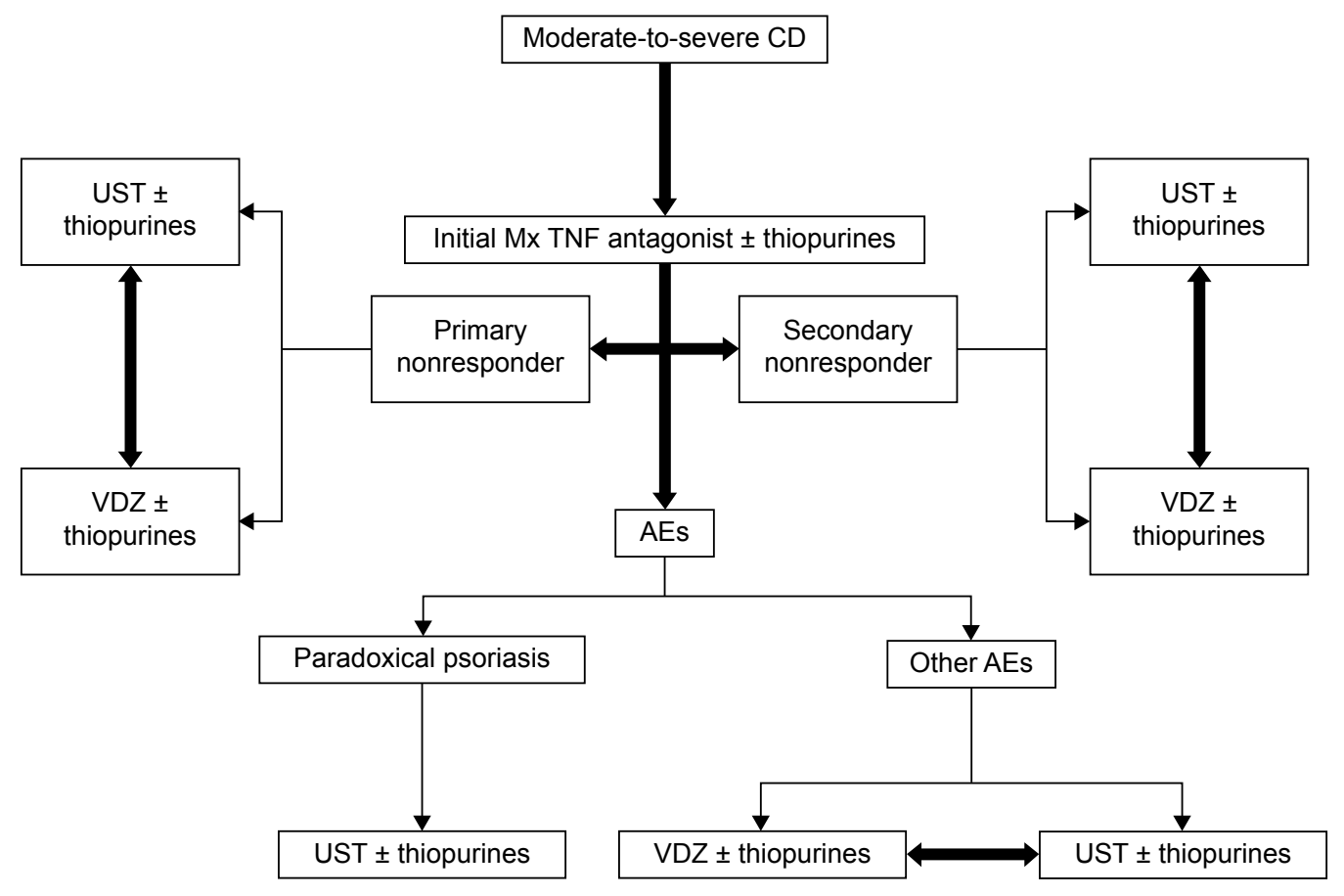

Figure 3 Proposed algorithm for use of UST in moderate-to-severe Crohn's disease.

Abbreviations: UST, ustekinumab; VDZ, vedolizumab; AEs, adverse events; TNF, tumor necrosis factor; CD, Crohn's disease.

superior efficacy of selective IL-23 blocker risankizumab (formerly investigational biologic compound BI 655066) over ustekinumab. ${ }^{82,83}$ After 9 months, $69 \%$ of patients with moderate-to-severe plaque psoriasis maintained clear or almost clear skin (PASI 90) with risankizumab in the higher dose group compared to $30 \%$ of patients on ustekinumab. The NAVIGATE clinical trial comparing the relative efficacy of ustekinumab to guselkumab (another selective IL-23 blocker) in patients with moderate-to-severe plaquetype psoriasis has been completed and results are awaited. ${ }^{84}$ Drugs specifically targeting the p19 subunit of IL-23 are being tested (risankizumab, MEDI2070) or will likely be tested (tildrakizumab and guselkumab) in $\mathrm{CD}$, to potentially increase safety by allowing for normal IL-12-mediated Th1 response..$^{85-88}$

\section{Future directions}

The effects of ustekinumab on healing of perianal disease and treating extra-intestinal manifestations are currently unknown. Additionally, development of predictive biomarkers for selecting patients likely to respond to ustekinumab may be the next step toward precision medicine in Crohn's disease, instead of a step-wise approach starting with TNF antagonists followed by ustekinumab or vedolizumab or vice versa. Serum soluble IL-2 receptor may be one such molecule. ${ }^{89}$

\section{Author contributions}

All authors contributed toward study conception, design, drafting and revising the paper and agree to be accountable for all aspects of the work.

\section{Disclosure}

Dr Loftus is a consultant for Janssen, Takeda, UCB, AbbVie, Amgen, Bristol-Myers Squibb, Eli Lilly, Mesoblast; research support from Janssen, Takeda, UCB, AbbVie, Genentech, Pfizer, Amgen, Robarts Clinical Trials, Gilead, Receptos, Seres, MedImmune. The authors report no other conflicts of interest in this work.

\section{References}

1. Abraham C, Cho JH. Inflammatory bowel disease. N Engl J Med. 2009; 361(21):2066-2078.

2. Xavier RJ, Podolsky DK. Unravelling the pathogenesis of inflammatory bowel disease. Nature. 2007;448(7152):427-434.

3. Feagan BG, Rochon J, Fedorak RN, et al. Methotrexate for the treatment of Crohn's disease. The North American Crohn's Study Group Investigators. N Engl J Med. 1995;332(5):292-297.

4. Present DH, Korelitz BI, Wisch N, Glass JL, Sachar DB, Pasternack BS Treatment of Crohn's disease with 6-mercaptopurine. A long-term, randomized, double-blind study. $N$ Engl J Med. 1980;302(18): 981-987

5. Peluso I, Pallone F, Monteleone G. Interleukin-12 and Th1 immune response in Crohn's disease: pathogenetic relevance and therapeutic implication. World J Gastroenterol. 2006;12(35):5606-5610.

6. Ryan C, Thrash B, Warren RB, Menter A. The use of ustekinumab in autoimmune disease. Expert Opin Biol Ther. 2010;10(4):587-604. 
7. Leonardi CL, Kimball AB, Papp KA, et al. Efficacy and safety of ustekinumab, a human interleukin-12/23 monoclonal antibody, in patients with psoriasis: 76-week results from a randomised, double-blind, placebocontrolled trial (PHOENIX 1). Lancet. 2008;371(9625):1665-1674.

8. Papp KA, Langley RG, Lebwohl M, et al. Efficacy and safety of ustekinumab, a human interleukin-12/23 monoclonal antibody, in patients with psoriasis: 52-week results from a randomised, double-blind, placebocontrolled trial (PHOENIX 2). Lancet. 2008;371(9625):1675-1684.

9. McInnes IB, Kavanaugh A, Gottlieb AB, et al. Efficacy and safety of ustekinumab in patients with active psoriatic arthritis: 1 year results of the phase 3, multicentre, double-blind, placebo-controlled PSUMMIT 1 trial. Lancet. 2013;382(9894):780-789.

10. Ritchlin C, Rahman P, Kavanaugh A, et al. Efficacy and safety of the anti-IL-12/23 p40 monoclonal antibody, ustekinumab, in patients with active psoriatic arthritis despite conventional non-biological and biological anti-tumour necrosis factor therapy: 6-month and 1-year results of the phase 3, multicentre, double-blind, placebo-controlled, randomised PSUMMIT 2 trial. Ann Rheum Dis. 2014;73(6):990-999.

11. Stelara ${ }^{\circledR}$ [package insert]. Horsham, PA: Janssen Biotech, Inc.; March 2014. Available from: https://www.stelarainfo.com/pdf/prescribinginformation.pdf. Accessed August 9, 2016.

12. Mannon PJ, Fuss IJ, Mayer L, et al. Anti-interleukin-12 antibody for active Crohn's disease. N Engl J Med. 2004;351(20):2069-2079.

13. Sandborn WJ, Gasink C, Gao LL, et al. Ustekinumab induction and maintenance therapy in refractory Crohn's disease. NEngl J Med. 2012; 367(16):1519-1528.

14. Sandborn WJ, Feagan BG, Fedorak RN, et al. A randomized trial of Ustekinumab, a human interleukin-12/23 monoclonal antibody, in patients with moderate-to-severe Crohn's disease. Gastroenterology. 2008;135(4):1130-1141.

15. FDA Approves STELARA ${ }^{\circledR}$ (ustekinumab) for Treatment of Adults with Moderately to Severely Active Crohn's Disease. Janssen Biotech, Inc. [press release]. PR Newswire; 2016 [September 26]. Available from: http://www.prnewswire.com/news-releases/fda-approves-stelaraustekinumab-for-treatment-of-adults-with-moderately-to-severelyactive-crohns-disease-300333868.html. Accessed October 7, 2016.

16. Trinchieri G. Interleukin-12 and the regulation of innate resistance and adaptive immunity. Nat Rev Immunol. 2003;3(2):133-146.

17. Kobayashi M, Fitz L, Ryan M, et al. Identification and purification of natural killer cell stimulatory factor (NKSF), a cytokine with multiple biologic effects on human lymphocytes. J Exp Med. 1989;170(3): $827-845$.

18. Presky DH, Yang H, Minetti LJ, et al. A functional interleukin 12 receptor complex is composed of two beta-type cytokine receptor subunits. Proc Natl Acad Sci U S A. 1996;93(24):14002-14007.

19. Parham C, Chirica M, Timans J, et al. A receptor for the heterodimeric cytokine IL-23 is composed of IL-12 Rbeta1 and a novel cytokine receptor subunit, IL-23R. J Immunol. 2002;168(11):5699-5708.

20. Aggarwal S, Ghilardi N, Xie MH, de Sauvage FJ, Gurney AL. Interleukin-23 promotes a distinct $\mathrm{CD} 4 \mathrm{~T}$ cell activation state characterized by the production of interleukin-17. J Biol Chem. 2003;278(3): 1910-1914.

21. Wilson NJ, Boniface K, Chan JR, et al. Development, cytokine profile and function of human interleukin 17-producing helper T cells. Nat Immunol. 2007;8(9):950-957.

22. Duvallet E, Semerano L, Assier E, Falgarone G, Boissier MC. Interleukin-23: a key cytokine in inflammatory diseases. Ann Med. 2011; 43(7):503-511.

23. Geremia A, Arancibia-Carcamo CV, Fleming MP, et al. IL-23responsive innate lymphoid cells are increased in inflammatory bowel disease. J Exp Med. 2011;208(6):1127-1133.

24. Benson JM, Sachs CW, Treacy G, et al. Therapeutic targeting of the IL-12/23 pathways: generation and characterization of ustekinumab. Nat Biotechnol. 2011;29(7):615-624.

25. Neurath MF, Fuss I, Kelsall BL, Stuber E, Strober W. Antibodies to interleukin 12 abrogate established experimental colitis in mice. $J$ Exp Med. 1995;182(5):1281-1290.
26. Uhlig HH, McKenzie BS, Hue S, et al. Differential activity of IL-12 and IL-23 in mucosal and systemic innate immune pathology. Immunity. 2006;25(2):309-318.

27. Becker C, Dornhoff H, Neufert C, et al. Cutting edge: IL-23 crossregulates IL-12 production in T cell-dependent experimental colitis. J Immunol. 2006;177(5):2760-2764.

28. Strober W, Fuss IJ. Proinflammatory cytokines in the pathogenesis of inflammatory bowel diseases. Gastroenterology. 2011;140(6): $1756-1767$.

29. Niederreiter L, Adolph TE, Kaser A. Anti-IL-12/23 in Crohn's disease: bench and bedside. Curr Drug Targets. 2013;14(12):1379-1384.

30. Wang W, Wang EQ, Balthasar JP. Monoclonal antibody pharmacokinetics and pharmacodynamics. Clin Pharmacol Ther. 2008;84(5): 548-558.

31. US FDA Center for Drug Evaluation and Research: Ustekinumab (2013). Available from: http://www.accessdata.fda.gov/drugsatfda docs/label/2013/125261s086lbl.pdf. Accessed July 18, 2016.

32. Gottlieb AB, Cooper KD, McCormick TS, et al. A phase 1, double-blind, placebo-controlled study evaluating single subcutaneous administrations of a human interleukin-12/23 monoclonal antibody in subjects with plaque psoriasis. Curr Med Res Opin. 2007;23(5):1081-1092.

33. Ordas I, Mould DR, Feagan BG, Sandborn WJ. Anti-TNF monoclonal antibodies in inflammatory bowel disease: pharmacokinetics-based dosing paradigms. Clin Pharmacol Ther. 2012;91(4):635-646.

34. Zhu Y, Hu C, Lu M, et al. Population pharmacokinetic modeling of ustekinumab, a human monoclonal antibody targeting IL-12/23p40, in patients with moderate to severe plaque psoriasis. J Clin Pharmacol. 2009;49(2):162-175.

35. Zhou H, Davis HM. Risk-based strategy for the assessment of pharmacokinetic drug-drug interactions for therapeutic monoclonal antibodies. Drug Discov Today. 2009;14(17-18):891-898.

36. Griffiths CE, Strober BE, van de Kerkhof P, et al. Comparison of ustekinumab and etanercept for moderate-to-severe psoriasis. $N$ Engl J Med. 2010;362(2):118-128.

37. Toedter GP, Blank M, Lang Y, Chen D, Sandborn WJ, de Villiers WJ. Relationship of C-reactive protein with clinical response after therapy with ustekinumab in Crohn's disease. Am J Gastroenterol. 2009; 104(11):2768-2773.

38. Feagan BG, Sandborn WJ, Gasink C, et al. Ustekinumab as Induction and Maintenance Therapy for Crohn's disease. N Engl J Med. 2016. In Press.

39. Sandborn W, Gasink C, Blank M, et al. O-001 A multicenter, doubleblind, placebo-controlled phase 3 study of ustekinumab, a human IL-12/23P40 mAB, in moderate-service Crohn's disease refractory to anti-TFNalpha: UNITI-1 (abstract). Inflamm Bowel Dis. 2016; 22(Suppl 1):S1.

40. Feagan B, Gasink C, Lang Y, et al. OP054-LB4 A multicenter, doubleblind, placebo-controlled $\mathrm{Ph} 3$ study of ustekinumab, a human monoclonal antibody to IL-12/23p 40 , in patients with moderately-severely active Crohn's disease who are naïve or not refractory to anti-TNFa: UNITI-2 (abstract). United European Gastroenterol J. 2015;3(6):2.

41. Sandborn W, Feagan BG, Gasink C, et al. 768 A phase 3 randomized, multicenter, double-blind, placebo-controlled study of ustekinumab maintenance therapy in moderate-severe Crohn's disease patients: results from IM-UNITI (abstract). Gastroenterology. 2016;150(4): S157-S158.

42. Batista DD, Yadav S, Harmsen WS, et al. Su1420 Ustekinumab treatment for Crohn's disease in clinical practice: experience at a tertiary medical center (abstract). Gastroenterology. 2014;146(5): S-464-S-465.

43. Kopylov U, Afif W, Cohen A, et al. Subcutaneous ustekinumab for the treatment of anti-TNF resistant Crohn's disease - the McGill experience. J Crohns Colitis. 2014;8(11):1516-1522.

44. Wils P, Bouhnik Y, Michetti P, et al. Subcutaneous ustekinumab provides clinical benefit for two-thirds of patients with Crohn's disease refractory to anti-tumor necrosis factor agents. Clin Gastroenterol Hepatol. 2016;14(2):242-250.e241-e242. 
45. Khorrami S, Ginard D, Marin-Jimenez I, et al. Ustekinumab for the treatment of refractory Crohn's disease: the Spanish experience in a large multicentre open-label cohort. Inflamm Bowel Dis. 2016;22(7): $1662-1669$.

46. Adedokun O, Xu Z, Gasink C, et al. Pharmacokinetics and exposureresponse relationships of intravenously administered ustekinumab during induction treatment in patients with Crohn's disease: results from the UNITI-1 and UNITI-2 studies (abstract). J Crohns Colitis. 2016;10:S23-S24.

47. Adedokun OJ, Xu Z, Gasink C, et al. Sa1934 Pharmacokinetics and exposure-response relationships of ustekinumab during IV induction and SC maintenance treatment of patients with Crohn's disease with ustekinumab: results from the UNITI-1, UNITI-2, and IM-UNITI studies (abstract). Gastroenterology. 2016;150(4):S408.

48. Battat R, Kopylov U, Bessissow T, et al. Association of ustekinumab trough concentrations with clinical, biochemical, and endoscopic outcomes (abstract). J Crohns Colitis. 2016;10:S74.

49. Langowski JL, Zhang X, Wu L, et al. IL-23 promotes tumour incidence and growth. Nature. 2006;442(7101):461-465.

50. Brunda MJ, Luistro L, Warrier RR, et al. Antitumor and antimetastatic activity of interleukin 12 against murine tumors. J Exp Med. 1993; 178(4):1223-1230.

51. Khanna R, Feagan BG. Ustekinumab for the treatment of Crohn's disease. Immunotherapy. 2013;5(8):803-815.

52. Papp KA, Griffiths CE, Gordon K, et al. Long-term safety of ustekinumab in patients with moderate-to-severe psoriasis: final results from 5 years of follow-up. Br J Dermatol. 2013;168(4):844-854.

53. Papp K, Gottlieb AB, Naldi L, et al. Safety surveillance for ustekinumab and other psoriasis treatments from the Psoriasis Longitudinal Assessment and Registry (PSOLAR). J Drugs Dermatol. 2015;14(7): 706-714.

54. Hinchey J, Chaves C, Appignani B, et al. A reversible posterior leukoencephalopathy syndrome. N Engl J Med. 1996;334(8):494-500.

55. Gratton D, Szapary P, Goyal K, Fakharzadeh S, Germain V, Saltiel P. Reversible posterior leukoencephalopathy syndrome in a patient treated with ustekinumab: case report and review of the literature. Arch Dermatol. 2011;147(10):1197-1202.

56. Loftus EV, Augustin M, Bissonnette R, et al. Mo1884 prevalence of inflammatory bowel disease among patients with psoriasis and incidence of serious infections in this subset: results from the PSOLAR registry (abstract). Gastroenterology. 2016;150(4):S805.

57. Ryan C, Leonardi CL, Krueger JG, et al. Association between biologic therapies for chronic plaque psoriasis and cardiovascular events: a meta-analysis of randomized controlled trials. JAMA. 2011;306(8): 864-871.

58. Badat Y, Meissner WG, Laharie D. Demyelination in a patient receiving ustekinumab for refractory Crohn's disease. J Crohns Colitis. 2014;8(9): 1138-1139.

59. McConnell RA, Mahadevan U. Use of immunomodulators and biologics before, during, and after pregnancy. Inflamm Bowel Dis. 2016;22(1): 213-223.

60. Martin PL, Sachs C, Imai N, et al. Development in the cynomolgus macaque following administration of ustekinumab, a human anti-IL12/23p40 monoclonal antibody, during pregnancy and lactation. Birth Defects Res B Dev Reprod Toxicol. 2010;89(5):351-363.

61. Schaufelberg BW, Horn E, Cather J, Rahawi K. Pregnancy outcomes in women exposed to ustekinumab in the psoriasis clinical development program (abstract). J Am Acad Dermatol. 2014;70(5):AB178.

62. Mahadevan U, Martin C, Kane SV, Dubinsky M, Sands BE, Sandborn W. 437 Do infant serum levels of biologic agents at birth correlate with risk of adverse outcomes? Results from the PIANO registry (abstract). Gastroenterology. 2016;150(4):S91-S92.

63. Nguyen GC, Seow CH, Maxwell C, et al. The Toronto consensus statements for the management of inflammatory bowel disease in pregnancy. Gastroenterology. 2016;150(3):734-757.e731.

64. Deepak P, Bruining DH. Update on the medical management of Crohn's disease. Curr Gastroenterol Rep. 2015;17(11):41.
65. Terdiman JP, Gruss CB, Heidelbaugh JJ, Sultan S, Falck-Ytter YT. American gastroenterological association institute guideline on the use of thiopurines, methotrexate, and anti-TNF-alpha biologic drugs for the induction and maintenance of remission in inflammatory Crohn's disease. Gastroenterology. 2013;145(6):1459-1463.

66. Ding NS, Hart A, De Cruz P. Systematic review: predicting and optimising response to anti-TNF therapy in Crohn's disease - algorithm for practical management. Aliment Pharmacol Ther. 2016;43(1): 30-51.

67. Ben-Horin S, Chowers Y. Review article: loss of response to anti-TNF treatments in Crohn's disease. Aliment Pharmacol Ther. 2011;33(9): 987-995.

68. Billioud V, Sandborn WJ, Peyrin-Biroulet L. Loss of response and need for adalimumab dose intensification in Crohn's disease: a systematic review. Am J Gastroenterol. 2011;106(4):674-684.

69. Sands BE, Feagan BG, Rutgeerts P, et al. Effects of vedolizumab induction therapy for patients with Crohn's disease in whom tumor necrosis factor antagonist treatment failed. Gastroenterology. 2014;147(3): 618-627.e613.

70. Sandborn WJ, Feagan BG, Rutgeerts P, et al. Vedolizumab as induction and maintenance therapy for Crohn's disease. N Engl J Med. 2013; 369(8):711-721.

71. Ben-Horin S, Casteele NV, Schreiber S, Lakatos P. Biosimilars in inflammatory bowel disease: facts and fears of extrapolation. Clin Gastroenterol Hepatol. 2016 Epub May 21.

72. Papamichael K, Van Stappen T, Jairath V, et al. Review article: pharmacological aspects of anti-TNF biosimilars in inflammatory bowel diseases. Aliment Pharmacol Ther. 2015;42(10):1158-1169.

73. Tillack C, Ehmann LM, Friedrich M, et al. Anti-TNF antibody-induced psoriasiform skin lesions in patients with inflammatory bowel disease are characterised by interferon-gamma-expressing Th1 cells and IL-17A/IL-22-expressing Th17 cells and respond to anti-IL-12/IL-23 antibody treatment. Gut. 2014;63(4):567-577.

74. Freling E, Baumann C, Cuny JF, et al. Cumulative incidence of, risk factors for, and outcome of dermatological complications of anti-TNF therapy in inflammatory bowel disease: a 14-year experience. Am J Gastroenterol. 2015;110(8):1186-1196.

75. Guerra I, Perez-Jeldres T, Iborra M, et al. Incidence, clinical characteristics, and management of psoriasis induced by anti-TNF therapy in patients with inflammatory bowel disease: a nationwide cohort study. Inflamm Bowel Dis. 2016;22(4):894-901.

76. Fahmy M, Ramamoorthy S, Hata T, Sandborn WJ. Ustekinumab for peristomal pyoderma gangrenosum. Am J Gastroenterol. 2012;107(5): 794-795.

77. Goldminz AM, Botto NC, Gottlieb AB. Severely recalcitrant pyoderma gangrenosum successfully treated with ustekinumab. J Am Acad Dermatol. 2012;67(5):e237-e238.

78. Guenova E, Teske A, Fehrenbacher B, et al. Interleukin 23 expression in pyoderma gangrenosum and targeted therapy with ustekinumab. Arch Dermatol. 2011;147(10):1203-1205.

79. Gheita TA, El G II, El-Fishawy HS, Aboul-Ezz MA, Kenawy SA. Involvement of IL-23 in enteropathic arthritis patients with inflammatory bowel disease: preliminary results. Clin Rheumatol. 2014;33(5): 713-717.

80. Levin AA, Gottlieb AB. Specific targeting of interleukin-23p19 as effective treatment for psoriasis. J Am Acad Dermatol. 2014;70(3): 555-561.

81. Campa M, Mansouri B, Warren R, Menter A. A review of biologic therapies targeting IL-23 and IL-17 for use in moderate-to-severe plaque psoriasis. Dermatol Ther. 2016;6(1):1-12.

82. Boehringer Ingelheim's investigational biologic cleared skin better, faster and for longer than ustekinumab in phase II psoriasis study. Boehringer Ingelheim, Inc. [press release]. Boehringer Ingelheim, Inc.; 2015 [October 8]. Available from: https://www.boehringeringelheim.com/press-release/boehringer-ingelheim-s-investigational-biologic-cleared-skin-better-faster-and-longer. Accessed October 7, 2016. 
83. Papp K, Menter A, Sofen H, et al. Efficacy and safety of different dose regimens of a selective IL-23p19 inhibitor (BI 655066) compared with ustekinumab in patients with moderate-to-severe plaque psoriasis with and without psoriatic arthritis (abstract). Arthritis Rheumatol. 2015;67(Suppl 10). Available from: http://acrabstracts.org/abstract/ efficacy-and-safety-of-different-dose-regimens-of-a-selective-il-23p19inhibitor-bi-655066-compared-with-ustekinumab-in-patients-withmoderate-to-severe-plaque-psoriasis-with-and-without-psoriatic-a/. Accessed October 9, 2016.

84. Janssen Research \& Development, LLC. A study of guselkumab in participants with moderate to severe plaque-type psoriasis and an inadequate response to ustekinumab (NAVIGATE). Bethesda (MD): National Library of Medicine (US); 2000 [cited 2016 Oct 7]. NLM Identifier: NCT02203032. Available from: https://www.clinicaltrials. gov/ct2/show/NCT02203032. Accessed October 7, 2016.

85. Sands BE, Chen J, Penney M, et al. 830 Initial evaluation of MEDI2070 (specific anti-IL-23 antibody) in patients with active Crohn's disease who have failed anti-TNF antibody therapy: a randomized, double-blind placebo-controlled phase 2A induction study (abstract). Gastroenterology. 2015;148(4):S-163-S-164.
86. Feagan BG, Sandborn W, Panés J, et al. 812a Efficacy and safety of induction therapy with the selective IL-23 inhibitor BI 655066, in patients with moderate-to-severe Crohn's disease: results of a randomized, double-blind, placebo-controlled phase II study (abstract). Gastroenterology. 2016;150(4):S1266.

87. Sun Pharma and Merck \& Co. Inc. Enter into Licensing Agreement for Tildrakizumab, Merck \& Co., Inc. [press release]. Merck Sharp \& Dohme Corp. website; 2014 [September 17]. Available from: http:// www.merck.com/licensing/our-partnership/sunpharma_partnership. html. Accessed October 7, 2016.

88. Sandborn WJ. The present and future of inflammatory bowel disease treatment. Gastroenterol Hepatol. 2016;12(7):438-441.

89. Kuehbacher T, Nikolaus S, Schreiber S. Serum soluble IL2-receptor is increased in a subpopulation of Crohns disease patients, who respond to open label use of ustekinumab, a human monoclonal antibody to IL-12/23p40 (abstract). Gastroenterology. 2011;140(5):S-589.
Drug Design, Development and Therapy

\section{Publish your work in this journal}

Drug Design, Development and Therapy is an international, peerreviewed open-access journal that spans the spectrum of drug design and development through to clinical applications. Clinical outcomes, patient safety, and programs for the development and effective, safe, and sustained use of medicines are the features of the journal, which

\section{Dovepress}

has also been accepted for indexing on PubMed Central. The manuscript management system is completely online and includes a very quick and fair peer-review system, which is all easy to use. Visit $\mathrm{http}: / /$ www.dovepress.com/testimonials.php to read real quotes from published authors.

Submit your manuscript here: http://www.dovepress.com/drug-design-development-and-therapy-journal 